\title{
Lanthanide discs chill well and relax slowly $\dagger$
}

\author{
Joseph W. Sharples, Yan-Zhen Zheng, Floriana Tuna, Eric J. L. McInnes and \\ David Collison*
}

Received 18th April 2011, Accepted 19th May 2011

DOI: $10.1039 / \mathrm{clcc12252 \textrm {e }}$

The synthesis, structure and magnetic properties of two isostructural heptametallic lanthanide discs are reported, showing single molecule magnet (SMM) behaviour with a large energy barrier for the dysprosium analogue and a large magnetocaloric effect (MCE) for the gadolinium analogue.

Transition metal clusters are being intensively studied because of their fascinating magnetic properties, including as molecular magnetic coolers ${ }^{1,2}$ or SMMs. ${ }^{3}$ There has been a recent increase in interest in lanthanides in these areas, in particular with dysprosium-based $\mathrm{SMMs}^{4}$ and gadolinium-containing mixed $\mathrm{d}-\mathrm{f}$ species as magnetic coolers. ${ }^{2,5}$ This exploits the large spins of $\mathrm{Ln}^{3+}$, and the choice of isotropic $\left[\right.$ e.g. $\mathrm{Gd}^{3+}$, favouring a large $\mathrm{MCE}]$ or anisotropic (e.g. $\mathrm{Dy}^{3+}$, favouring a large energy barrier to relaxation) magnetic behaviour. The similarity in size of $\mathrm{Dy}^{3+}$ and $\mathrm{Gd}^{3+}$ ions should make it possible to isolate isostructural species showing one or other of these properties; however, examples of this are rare. ${ }^{6}$ Here, we report isostructural heptametallic clusters with disc-like structures. When $\mathrm{Ln}=\mathrm{Gd}$ a large MCE is found, when Ln = Dy the molecule is a SMM.

Solvothermal ${ }^{7}$ reactions of $\mathrm{Ln}\left(\mathrm{NO}_{3}\right)_{3} \cdot 5 \mathrm{H}_{2} \mathrm{O}(0.1 \mathrm{~g}, 0.22 \mathrm{mmol})$ with the tripodal alcohol thmeH $\mathrm{H}_{3}$ [tris(hydroxymethyl)ethane, Fig. S1†; $0.11 \mathrm{mmol}$, triphenylacetic acid (tpaH; $0.11 \mathrm{mmol})$ and $\mathrm{NEt}_{3}(0.165 \mathrm{mmol})$ in $\mathrm{MeCN}(8 \mathrm{~mL})$ at $100{ }^{\circ} \mathrm{C}$ give colourless crystals of 1 or 2 ( $\mathrm{Ln}=$ Dy or Gd, respectively; $c a .50 \%)$. Single crystal X-ray diffraction shows these to be $\left[\mathrm{Ln}_{7}(\mathrm{OH})_{6}\left(\mathrm{thmeH}_{2}\right)_{5}\right.$ $\left(\right.$ thmeH) $\left.(\text { tpa })_{6}(\mathrm{MeCN})_{2}\right]\left(\mathrm{NO}_{3}\right)_{2}$ (Fig. 1). The clusters have centred-hexagonal $\mathrm{Ln}_{7}$ cores (Fig. S2 $\dagger$ ). This topology has been seen for $3 \mathrm{~d}$ metals including $\mathrm{Ni}, \mathrm{Fe}, \mathrm{Cu}, \mathrm{Co}$ and $\mathrm{Mn},{ }^{8}$ but not for Ln (although "empty" $\mathrm{Ln}_{6}$ rings are known). ${ }^{9}$ The molecule lies on a crystallographic inversion centre; the central $\mathrm{Ln}^{3+}$ ion lies just out of the $\mathrm{Ln}_{6}$ plane (and hence is disordered over two sites).

The peripheral and central $\mathrm{Ln}$ ions are bound by six $\mu_{3}-\mathrm{OH}$ groups, alternating above and below the $\mathrm{Ln}_{7}$ plane. Each edge of the $\mathrm{Ln}_{6}$ hexagon is bridged by a triphenylacetate and a $\left(\mathrm{thmeH}_{2}\right)^{-}$ ligand. The latter are singly deprotonated, the alkoxide arm $\mu_{2}$-bridging while the protonated arms each bind terminally to

School of Chemistry, The University of Manchester, Oxford Road, Manchester, M13 9PL, United Kingdom.

E-mail: david.collison@manchester.ac.uk;

Fax: + 44 (0) 161275 4598; Tel: + 44 (0) 1613069260

$\dagger$ Electronic supplementary information (ESI) available: Further structural views and magnetic data. CCDC 823957-823958. For ESI and crystallographic data in CIF or other electronic format see DOI: $10.1039 / \mathrm{clcc} 12252 \mathrm{e}$

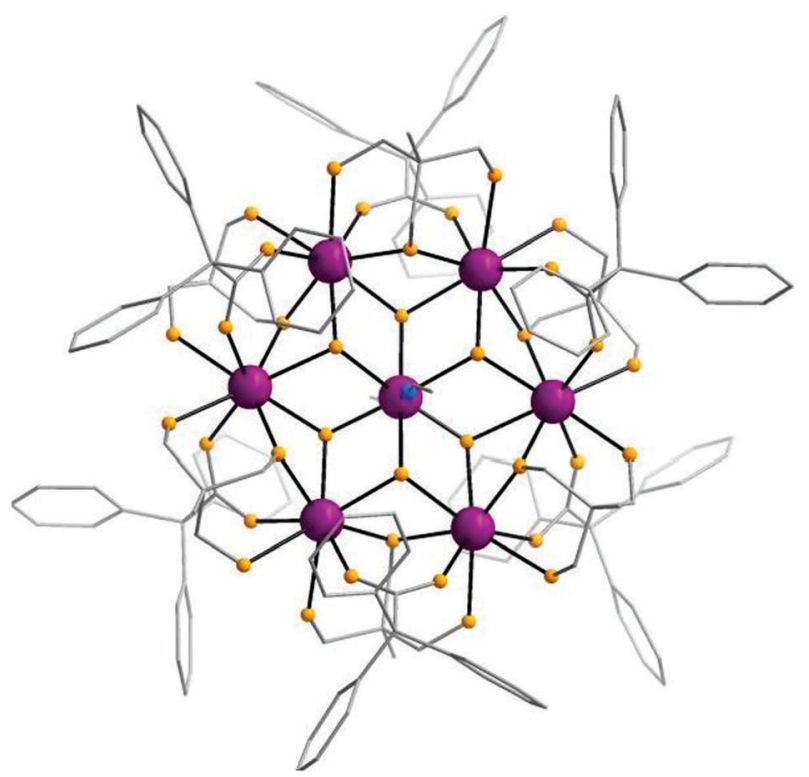

Fig. 1 Structure of $\left[\mathrm{Gd}_{7}(\mathrm{OH})_{6}\left(\mathrm{thmeH}_{2}\right)_{5}(\right.$ thmeH $)(\mathrm{tpa})_{6}\left(\mathrm{MeCN}_{2}\right]^{2+}$ (2). Scheme: Gd (purple), O (yellow), N (blue), C (skeletal), H not shown.

one of the Ln ions. Charge balance requires that only one ligand must lose an additional proton, but this must be disordered. Although thme $\mathrm{H}_{3}$ has been used extensively in $3 \mathrm{~d}$ metal cluster chemistry, ${ }^{10}$ to the best of our knowledge this is the first example of a homometallic $4 \mathrm{f}$ cluster incorporating this ligand. The central Ln ion has two terminal MeCN groups, making all metal ions eight co-ordinate. The coordination geometry at the central ion approximates closely to 3 -fold symmetric (Fig. S3†). The cluster is a dication, with nitrates providing the charge balance.

We start with the magnetic properties of $\mathbf{2}$ containing the spin-only $\mathrm{Gd}^{3+}$ ion. At room temperature $\chi_{\mathrm{M}} T\left(\chi_{\mathrm{M}}\right.$ is the molar magnetic susceptibility) is $54.3 \mathrm{~cm}^{3} \mathrm{~K} \mathrm{~mol}^{-1}$ (Fig. 2), in agreement with the value for seven uncoupled $s=7 / 2$ ions with $g=2.0$. On cooling, $\chi_{\mathrm{M}} T$ decreases slowly until ca. $30 \mathrm{~K}$ where it decreases more rapidly. We have not attempted to model the data given the $8^{7}$-dimensional spin system, but it is only consistent with weak antiferromagnetic coupling between the $\mathrm{Gd}^{3+}$ ions. The low temperature molar magnetisation $(M)$ saturates at $49 \mu_{\mathrm{B}}$ above ca. $6 \mathrm{~T}$ (Fig. $\mathrm{S} 4 \dagger$ ). Note that this does not indicate an $S=49 / 2$ ground state, simply that this state becomes the ground state in these applied fields. The centred-hexagonal topology, consisting of six edge-sharing triangles is highly frustrated and this, combined with the weak antiferromagnetic nature of the coupling, will give 


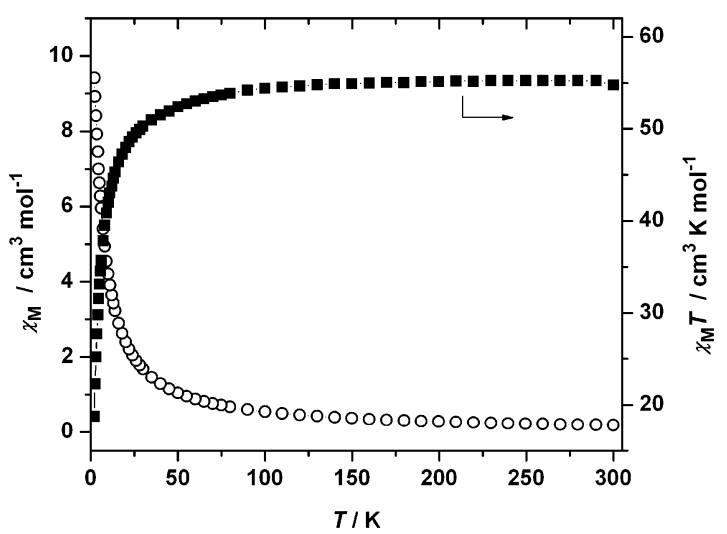

Fig. $2 \chi_{M} T(T)(\mathbb{\square})$ and $\chi_{M}(T)(\bigcirc)$ for 2 at $\mathrm{H}=500 \mathrm{G}$.

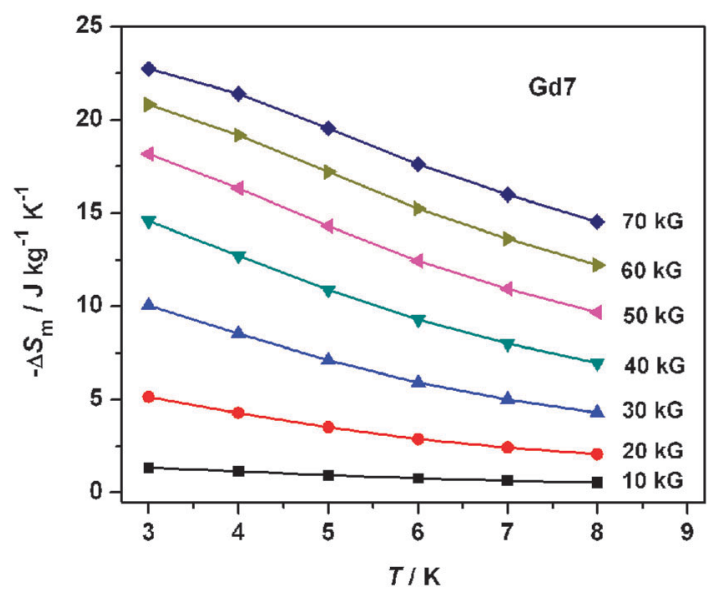

Fig. 3 Calculated $-\Delta S_{m}(T)$ for 2 at various fields (10-70 kG).

rise to many low-lying states that are populated even at base temperature. The maximum spin state $(S=49 / 2)$ will then become the ground state in relatively small applied magnetic fields. This situation is promising for a large low-temperature MCE because the possible magnetic entropy change on magnetisation is enhanced by the multiple low-lying states that are thermally accessible in zero-field (large entropy) while the magnetisation can still be saturated (nil entropy) in applied field. ${ }^{1,5 a}$

We have calculated the magnetic entropy change $-\Delta S_{\mathrm{m}}$ for various field changes and temperatures from the $M(H, T)$ data (Fig. 3). The maximum change, at $3 \mathrm{~K}$ and for a field change of $0-7 \mathrm{~T}$, is $23 \mathrm{~J} \mathrm{~kg}^{-1} \mathrm{~K}^{-1}$. This compares against 26 and $31 \mathrm{~J} \mathrm{~kg}^{-1} \mathrm{~K}^{-1}$, the largest values reported to date, for $\mathrm{Ni}_{6} \mathrm{Gd}_{6}$ $(\Delta H=7 \mathrm{~T}$ at $3 \mathrm{~K})$ and $\mathrm{Cu}_{5} \mathrm{Gd}_{4}(\Delta H=9 \mathrm{~T}$ at $3 \mathrm{~K})$ clusters. ${ }^{2}$ This $-\Delta S_{\mathrm{m}}$ value, equivalent to $10.6 \mathrm{R}$ where $\mathrm{R}$ is the gas constant, is much larger than that expected for an $S=49 / 2$ paramagnet (3.9 R), showing the massive enhancement due to the high density of low-lying states in low fields, a result of the weak coupling and spin frustration. The maximum possible value for seven $\mathrm{Gd}^{3+}$ ions is $14.6 \mathrm{R}$.

However, a disadvantage of the antiferromagnetic nature of the coupling is shown by comparison of the experimental low temperature $M(H)$ curves against the calculated Brillouin curves for seven uncoupled $s=7 / 2$ ions (Fig. S4 $\dagger$ ). The antiferromagnetic coupling leads to slower magnetisation as a function of applied field $c f$. uncoupled ions. This would translate as a slower cooling rate. The conclusion is that a weakly ferromagnetically

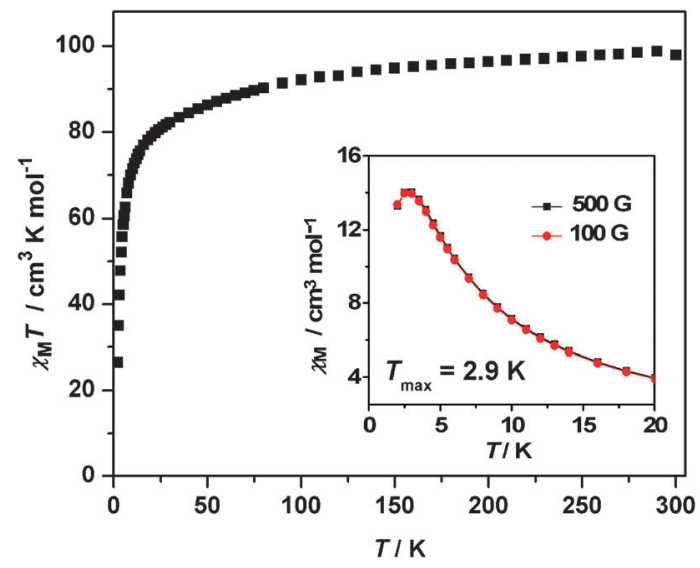

Fig. $4 \chi_{\mathrm{M}} T(T)$ of 1 in $500 \mathrm{G}$ applied magnetic field. Inset: $\chi_{\mathrm{M}}(T)$.

coupled system would be ideal for magnetic cooling, coupling the advantages of low-lying excited states with ease of magnetisation. A recent example is Murray's $\mathrm{Cu}_{5} \mathrm{Gd}_{4}$ cluster. ${ }^{2 b}$

For the isostructural $\mathrm{Dy}_{7}$ analogue $1, \chi_{\mathrm{M}} T$ is $98.0 \mathrm{~cm}^{3} \mathrm{~K} \mathrm{~mol}^{-1}$ at room temperature (Fig. 4), in good agreement with the calculated value of $99.2 \mathrm{~cm}^{3} \mathrm{~K} \mathrm{~mol}{ }^{-1}$ for seven uncoupled Dy ${ }^{\text {III }}$ ions $\left({ }^{6} \mathrm{H}_{15 / 2}\right.$ ground term, $\left.g=4 / 3\right) \cdot \chi_{M} T$ decreases gradually on cooling, then more rapidly below $30 \mathrm{~K}$. This indicates either weak antiferromagnetic interactions and/or depopulation of the Dy $^{3+}$ excited Stark sub-levels. ${ }^{11} \chi_{\mathrm{M}}(T)$ displays a maximum at $2.9 \mathrm{~K}$ (Fig. 4, inset) which shifts to lower temperatures for applied fields $>3 \mathrm{kG} . M(H)$ approaches saturation at $c a .36 \mu_{\mathrm{B}}$ at low temperature (Fig. S5 $\dagger$ ). Reduced magnetisation curves do not superimpose, suggesting the presence of significant magnetic anisotropy and/or low-lying excited states.

The magnetization dynamics were investigated by alternating current (ac) susceptibility measurements as a function of temperature $(2-25 \mathrm{~K})$ and frequency $(\nu=0.1-1400 \mathrm{~Hz})$, in zero dc field (Fig. 5 and $S 6 \dagger$ ). Both the in-phase $\left(\chi_{M}^{\prime}\right)$ and out-ofphase $\left(\chi_{\mathrm{M}}{ }^{\prime \prime}\right)$ components of the susceptibility show frequency dependence below ca. $28 \mathrm{~K}$; maxima are observed in $\chi_{\mathrm{M}}{ }^{\prime \prime}(T)$. These observations are characteristic of SMM behaviour.

Although at lower frequencies only a single peak is observed in $\chi_{\mathrm{M}}{ }^{\prime \prime}(T)($ e.g. at $3 \mathrm{~K}$ for $1 \mathrm{~Hz}$; Fig. 5), multiple peaks are observed at higher frequencies (at 2.9 and $14.1 \mathrm{~K}$, with a shoulder at $24 \mathrm{~K}$, for $\nu=1.2 \mathrm{kHz}$ ) indicating multiple relaxation processes. This is likely due to the presence of two types of $\mathrm{Dy}^{3+}$ ion, the central ion and peripheral sites, because their anisotropy axes are not expected to be collinear. ${ }^{12,13}$ Relaxation time constant $(\tau)$ data, evaluated from $\chi_{\mathrm{M}}{ }^{\prime \prime}(T, \nu)$, are linear with $1 / T$ above $10.5 \mathrm{~K}$ (Fig. 5): fitting to an Arrhenius law gives a thermal energy barrier to magnetisation relaxation $U_{\text {eff }}=140 \mathrm{~K}$ with $\tau_{0}=7.2 \times 10^{-9} \mathrm{~s}$. This is among the highest observed for a cluster SMM, exceeded only by two $\mathrm{Dy}_{4}\left(U_{\text {eff }} c a .170 \mathrm{~K}\right),{ }^{12} \mathrm{a} \mathrm{Dy}_{6}(200 \mathrm{~K}),{ }^{13}$ and the recent observation of $530 \mathrm{~K}$ in a Dy ${ }_{5}$ cluster. ${ }^{14}$ Higher barriers have been reported for high symmetry monometallic $\mathrm{Tb}^{3+}$ complexes. ${ }^{15}$

Below $10 \mathrm{~K}, \tau$ tends to saturate, suggesting a quantum tunneling relaxation pathway. This is supported by fielddependence studies at $1.8 \mathrm{~K}$, which show a minimum in $\tau$ in zero applied field, and is also consistent with the lack of hysteresis in $M(H)$ at $1.8 \mathrm{~K}$ (Fig. S7 $\dagger$ ). The latter has an inflection point at $4.3 \mathrm{kG}$, presumably indicating a level crossing. The onset of quantum behaviour is also reflected in Cole-Cole 


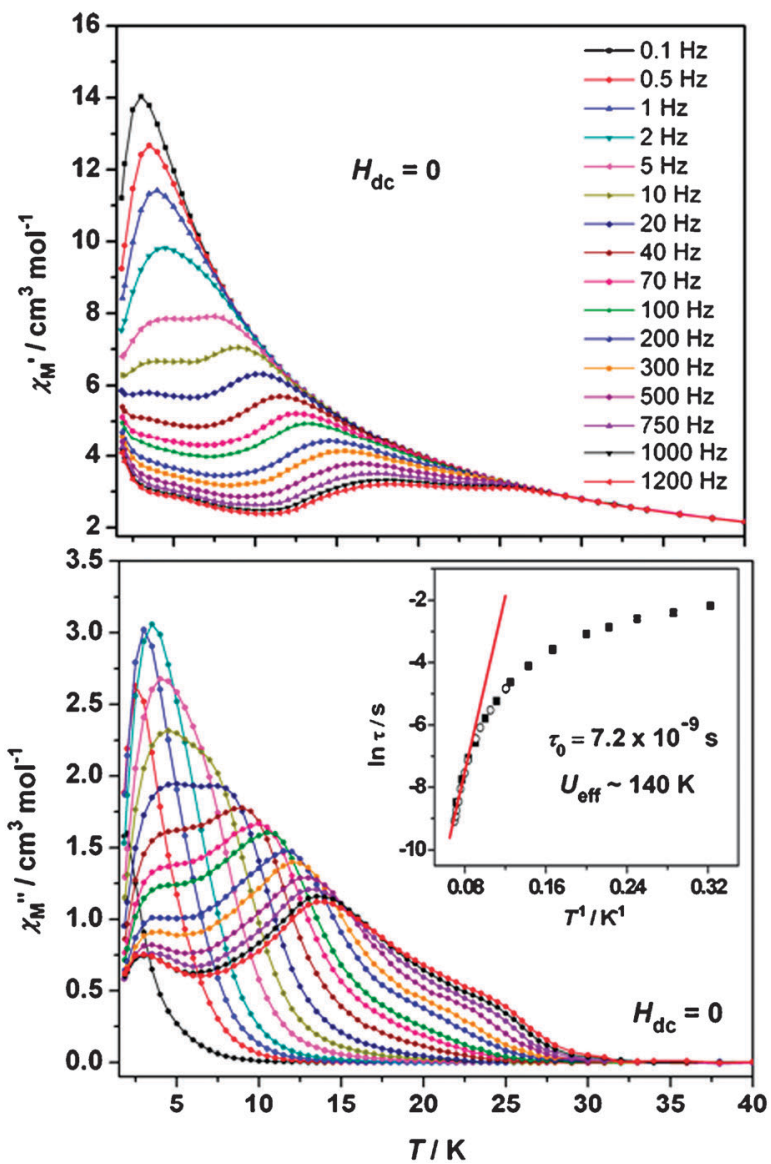

Fig. 5 Temperature dependence of: (top) $\chi_{\mathrm{M}}{ }^{\prime}$ and (bottom) $\chi_{\mathrm{M}}{ }^{\prime \prime}$ for $\mathbf{1}$, measured in $1.55 \mathrm{G}$ ac field and zero dc field. Inset: $\tau\left(T^{-1}\right)$ for $\mathbf{1}$, under zero dc field, based on data collected in frequency $(\boldsymbol{\square})$ and temperature $(\bigcirc)$ variation regimes, and best fit to the Arrhenius law of the thermally activated region (solid line).

diagrams and the fitted $\alpha$ parameters (Fig. S8 $\dagger$ ). Below $10 \mathrm{~K}$ the plots are asymmetric and $\alpha$ increases with decreasing temperature; between 18 and $10 \mathrm{~K} \alpha$ is almost constant at 0.22 . We can speculate that at the higher temperatures the slow relaxation is dominated by the single ion behaviour of the central (highly symmetric) $\mathrm{Dy}^{3+}$ ion, while at low temperatures the weak coupling with the peripheral ions is important.

In summary, two isostructural heptametallic lanthanide discs have been made. Magnetic investigations show a significant MCE for the $\mathrm{Gd}_{7}$ disc and slow relaxation behaviour with a high thermal energy barrier for the $\mathrm{Dy}_{7}$ analogue. Further analysis of the complicated $\mathrm{Dy}_{7}$ dynamic behaviour will require single crystal magnetic studies, including of doped diamagnetic and isostructural analogues: efforts towards this are underway.

We are grateful to the EPSRC (UK) and the EC (Marie Curie International Incoming Fellowship to YZZ) for funding, and to the referees for helpful comments.

\section{Notes and references}

$\ddagger$ Elemental analyses (calc: found): (1) Dy $29.29: 28.78, \mathrm{C} 47.63: 47.18, \mathrm{H}$ $4.33: 3.77$, N 1.44:1.29; (2) Gd 28.61:27.25, C 48.08:46.08, H 4.38:4.26,

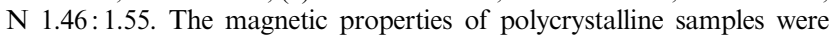
investigated in the temperature range 1.8-300 K using a Quantum Design MPMS-XL SQUID magnetometer; loose samples tended to orient in the magnetic field and hence were fixed in eicosane. Data are corrected for the diamagnetism of the compounds (Pascal constants) and sample holder and eicosane by measurement. $A c$ susceptibility measurements were performed with an $a c$ magnetic field of $1.55 \mathrm{G}$ oscillating at frequencies ranging from 1 to $1400 \mathrm{~Hz}$.

Crystal data. For $\mathbf{1}, \mathrm{C}_{154} \mathrm{H}_{164} \mathrm{Dy}_{7} \mathrm{~N}_{4} \mathrm{O}_{42}, M=3880.39$, monoclinic, space group $P \overline{1}, T=100(2) \mathrm{K}, a=16.263(4), b=16.500(4)$, $c=17.299(4) \AA, \alpha=97.2170(10)^{\circ}, \beta=113.906(4)^{\circ}, \gamma=$ $115.0080(10)^{\circ}, V=3590.4(15) \AA^{3}, Z=1, \rho=1.795 \mathrm{~g} \mathrm{~cm}^{-3}$, total data 29169 , unique data $12278\left(R_{\text {int }}=0.1473\right), \mu=3.680 \mathrm{~mm}^{-1}$, 937 parameters, $R_{1}=0.0725$ for $I \geq 2 \sigma(I)$ and $\mathrm{w} R_{2}=0.2585$ for all data. For $2, \mathrm{C}_{154} \mathrm{H}_{164} \mathrm{Gd}_{7} \mathrm{~N}_{4} \mathrm{O}_{42}, M=3843.64$, triclinic, space group $P \overline{1}, T=100(2) \mathrm{K}, a=16.1991(8), b=16.3943(8), c=17.2829(9) \AA$, $\alpha=97.2230(10)^{\circ}, \quad \beta=113.8990(10)^{\circ}, \quad \gamma=114.9720(10)^{\circ}$, $V=3551.8(3) \AA^{3}, Z=1, \rho=1.797 \mathrm{~g} \mathrm{~cm}^{-3}$, total data 24854 , unique data $12349\left(R_{\text {int }}=0.0685\right), \mu=3.306 \mathrm{~mm}^{-1}, 937$ parameters, $R_{1}=$ 0.1013 for $I \geq 2 \sigma(I)$ and $w R_{2}=0.2293$ for all data. The data of $\mathbf{1}$ and $\mathbf{2}$ were recorded on a Bruker SMART CCD diffractometer with Mo-K $\alpha$ radiation $(\lambda=0.71073 \AA)$. The structures were solved by direct methods and refined on $F^{2}$ using SHELXTL. CCDC 823957 and 823958 contain the supplementary crystallographic data for this paper. These data can be obtained free of charge via www.ccdc.cam.ac.uk/conts/retrieving.html (or from the Cambridge Crystallographic Data Centre, 12 Union Road, Cambridge CB21EZ, UK; fax: (+44)1223-336-033; or deposit@ ccdc.cam.ac.uk).

1 R. Shaw, R. H. Laye, L. F. Jones, D. M. Low, C. Talbot-Eeckelaers, Q. Wei, C. J. Milios, S. Teat, M. Helliwell, J. Raftery, M. Evangelisti, M. Affronte, D. Collison, E. K. Brechin and E. J. L. McInnes, Inorg. Chem., 2007, 46, 4968; M. Evangelisti, A. Candini, A. Ghirri, M. Affronte, E. K. Brechin and E. J. L. McInnes, Appl. Phys. Lett., 2005, 87, 072504.

2 (a) Y.-Z. Zheng, M. Evangelisti and R. E. P. Winpenny, Angew. Chem., Int. Ed., 2011, 50, 3692; (b) S. K. Langley, N. F. Chilton, B. Moubaraki, T. Hooper, E. K. Brechin, M. Evangelisti and K. S. Murray, Chem. Sci., 2011, 2, 1166.

3 G. Aromí and E. K. Brechin, Struct. Bonding, 2006, 122, 1.

4 (a) R. Sessoli and A. K. Powell, Coord. Chem. Rev., 2009, 253, 2328; (b) J. D. Reinhart, M. Fang, W. J. Evans and J. R. Long, Nat. Chem., 2011, DOI: 10.1038/NCHEM.1063.

5 (a) M. Evangelisti and E. K. Brechin, Dalton Trans., 2010, 39, 4672; (b) G. Karotsis, M. Evangelisti, S. J. Dalgarno and E. K. Brechin, Angew. Chem., Int. Ed., 2009, 48, 9928; (c) Y.-Z. Zheng, M. Evangelisti and R. E. P. Winpenny, Chem. Sci., 2011, 2, 99.

6 C. M. Liu, D. Q. Zhang and D. B. Zhu, Dalton Trans., 2010, 39, 11325.

7 R. H. Laye and E. J. L. McInnes, Eur. J. Inorg. Chem., 2004, 2811.

8 S. T. Meally, G. Karotsis, E. K. Brechin, G. S. Papaefstathiou, P. W. Dunne, P. McArdle and L. F. Jones, CrystEngComm, 2010, 12, 59; L. F. Jones, P. Jensen, B. Moubaraki, K. J. Berry, J. F. Boas, J. R. Pilbrow and K. S. Murray, J. Mater. Chem., 2006, 16, 2690; J. J. Henkelis, L. F. Jones, M. P. de Miranda, C. A. Kilner and M. A. Halcrow, Inorg. Chem., 2010, 49, 11127; M. Moragues-Canovas, C. E. Talbot-Eeckelaers, L. Catala, F. Lloret, W. Wernsdorfer, E. K. Brechin and T. Mallah, Inorg. Chem., 2006, 45, 7038; N. C. Harden, M. A. Bolcar, W. Wernsdorfer, K. A. Abboud, W. E. Streib and G. Christou, Inorg. Chem., 2003, 42, 7067.

9 S. K. Langley, B. Moubaraki, C. M. Forsyth, I. A. Gass and K. S. Murray, Dalton Trans., 2010, 39, 1705.

10 E. K. Brechin, Chem. Commun., 2005, 5141.

11 J. Luzon, K. Bernot, I. J. Hewitt, C. E. Anson, A. K. Powell and R. Sessoli, Phys. Rev. Lett., 2008, 100, 247205.

12 (a) P.-H. Lin, T. J. Burchell, L. Ungur, L. F. Chibotaru, W. Wernsdorfer and M. Murugesu, Angew. Chem., Int. Ed., 2009, 48, 9489; (b) Y.-N. Guo, G.-F. Xu, P. Gamez, L. Zhao, S.-Y. Lin, R. Deng, J. Tang and H.-J. Zhang, J. Am. Chem. Soc., 2010, 132, 8538.

13 I. J. Hewitt, J. Tang, N. T. Madhu, C. E. Anson, Y. Lan, J. Luzon, M. Etienne, R. Sessoli and A. K. Powell, Angew. Chem., Int. Ed., 2010, 49, 6352 .

14 R. Blagg, C. A. Muryn, E. J. L. McInnes, F. Tuna and R. E. P. Winpenny, Angew. Chem. Int. Ed., 2011, DOI: 10.1002/ anie.201101932.

15 (a) N. Ishikawa, M. Sugita, N. Tanaka, T. Ishikawa, S.-Y. Koshihara and Y. Kaizu, Inorg. Chem., 2004, 43, 5498; (b) S. Takamatsu, T. Ishikawa, S.-Y. Koshihara and N. Ishikawa, Inorg. Chem., 2007, 46, $7250 . z$ 